\title{
Adipokines secretion in feline primary adipose tissue culture in response to dietary fatty acids
}

\author{
M. Mazaki-Tovi ${ }^{1,2^{*}}$ (D, S. R. Bolin ${ }^{1}$ and P. A. Schenck ${ }^{1,3}$
}

\begin{abstract}
Background: Obesity in cats has been associated with alterations in adipokines including: adiponectin, interleukin-6 (IL6), and tumor necrosis factor-a (TNFa). Omega-3 polyunsaturated fatty acids have multiple beneficial effects on obesityassociated disorders, and therefore may alleviate these alterations. This study aimed to determine the effects of body condition, fat depot, troglitazone, and different fatty acids on secretion of adiponectin, IL6 and TNFa from adipose tissue of healthy cats. Subcutaneous and visceral adipose tissue samples were collected from 18 healthy intact female cats, and body condition score (Range 3-7/9) was determined. Concentrations of adiponectin were measured in mature adipocytes cultures and concentrations of IL6 and TNFa were measured in stromovascular cells cultures following treatment with control medium, troglitazone at $10 \mu \mathrm{M}$, eicosapentaenoic acid, arachidonic acid, or palmitic acid, at 25, 50, or $100 \mu \mathrm{M}$.

Results: Stromovascular cells of visceral origin secreted higher concentrations of IL6 than corresponding cells of subcutaneous origin $(P=0.003)$. Arachidonic acid treatment at 25,50 , and $100 \mu \mathrm{M}$ increased IL6 secretion in subcutaneous ( $P=0.045, P=0.002$, and $P<0.001$, respectively) and visceral $(P=0.034, P=0.001$, and $P<0.001$, respectively) stromovascular cells. Eicosapentaenoic acid treatment increased TNFa secretion in subcutaneous stromovascular cells at 25, 50, and $100 \mu \mathrm{M}$ $(P=0.002, P=0.001$, and $P=0.015$, respectively) and in visceral stromovascular cells at $50 \mu \mathrm{M}(P<0.001)$. No significant effect on medium adiponectin concentration was observed following troglitazone treatment $(P=0.4)$ or fatty acids treatments at $25(P=0.2), 50(P=0.8)$, or $100(P=0.7) \mu \mathrm{M}$. Body condition score did not have significant effects on medium concentrations of adiponectin $(P=0.4)$, IL6 $(P=0.1)$, or TNFa $(P=0.8)$.

Conclusions: This study demonstrated higher basal secretion of IL6 from visceral compared to subcutaneous adipose tissue, a stimulatory effect of arachidonic acid on secretion of IL6 and a stimulatory effect of eicosapentaenoic acid on TNFa from feline adipose tissue.
\end{abstract}

Keywords: Adipogenesis, Cytokines, N-3 fatty acids, N-6 fatty acids, Saturated fatty acids

\section{Background}

Adipose tissue has an important role in energy homeostasis by serving as a storage organ as well as through secretion of adipokines, including adiponectin, interleukin-6 (IL6), and tumor necrosis factor- $\alpha$ (TNF $\alpha$ ). It is a heterogeneous tissue comprised of various types of cells, including mature adipocytes and stromovascular cells (SVC,

\footnotetext{
*Correspondence: michal.tovi@mail.huji.ac.il

'Department of Pathobiology and Diagnostic Investigation, Diagnostic Center for Population and Animal Health College of Veterinary Medicine, Michigan State University, East Lansing, MI 48824, USA

2Present address: Hebrew University Veterinary Teaching Hospital, Koret School of Veterinary Medicine, The Hebrew University of Jerusalem, P.O. Box 12, 76100 Rehovot, Israel

Full list of author information is available at the end of the article
}

preadipocytes, fibroblasts and undifferentiated mesenchymal stem cells, endothelial cells, and macrophages). Adiponectin is synthesized and secreted predominantly by mature adipocytes [1]. It has profound effects to increase insulin sensitivity and decrease lipid concentrations [2] as well as anti-inflammatory and anti-atherosclerotic properties $[3,4]$. Interleukin- 6 and TNF $\alpha$ are produced by the SVC [5, 6], mainly the macrophages [7].These proinflammatory cytokines also display multiple effects on carbohydrate and lipid metabolism, leading to impairment of insulin sensitivity [8] and accelerated lipolysis [9].

The nuclear receptor peroxisome proliferator-activated receptor $\gamma$ (PPAR $\gamma$ ) is expressed predominantly in the adipose tissue, where it has an important role in glucose 
and lipid homeostasis [10], and also in macrophages, where it inhibits cellular activation [11]. In cats, expression of PPAR $\gamma$ mRNA was demonstrated in adipose tissue [12] and pharmacological agonists were shown to improve insulin sensitivity and lipid metabolism [13, 14], and to increase adiponectin concentrations [14]. In addition, agonists of PPAR $\gamma$ have been shown to increase circulating adiponectin concentrations and to decrease TNF $\alpha$ concentrations in diabetic human patients $[15,16]$.

Obesity in cats, similar to other species, has been associated with decreased adipose tissue mRNA expression and circulating concentrations of adiponectin as well as increased adipose tissue expression of TNF $\alpha$ and IL6 [17-20]. Low adiponectin concentrations and systemic low-grade inflammation have been suggested in the pathogenesis of several obesity-associated metabolic disorders in humans, including insulin resistance, hepatic steatosis, dyslipidemia, and atherosclerosis [4, 21, 22]. In cats, insulin resistance [17] and diabetes mellitus [23] were associated with decreased adiponectin concentrations, whereas hepatic lipidosis [24] was associated with increased adiponectin concentrations that were suggested to be related to hepatic injury, rather than lipidosis specifically.

Omega-3 polyunsaturated fatty acids (n3PUFA) have multiple beneficial effects on obesity-associated disorders in humans and animals. Feeding an n3PUFA rich diet to obese cats resulted in improved insulinsensitivity compared to a diet rich in saturated fatty acids (SFA) [25]. In humans, in addition to an insulinsensitizing effect, n3PUFA have been shown to have cardioprotective, hypolipidemic, and anti-inflammatory effects [26-29].

In view of the beneficial effects of n3PUFA in disorders that are associated with decreased concentration of adiponectin and increased concentrations of IL6 and TNF $\alpha$, it is possible that these alterations may be ameliorated by n3PUFA. The aim of this study was to determine the effect of fat depot, body condition and fatty acids (FA) on secretion of adiponectin, IL6, and TNF $\alpha$ from feline adipose tissue.

\section{Results}

\section{Cats and cultures}

All cats were mixed breed. Age was estimated to range from 6 to 18 months. Body condition score (BCS) ranged from 3 to 7 (Median: 5). BCS distribution was as follows: $3(n=1), 5(n=9), 6(n=7), 7(n=1)$.

The packed adipocytes volume (PAV) ranged from 2 to $8 \%$ (median: 5\%). No significant effect of PAV on medium adiponectin concentrations was demonstrated in the analysis of the effect of BCS, fat depot and troglitazone treatment $(P=0.3)$ or the analyses of the effect of fatty acids (FA) treatment at $25 \mu \mathrm{M}(P=$ $0.9), 50 \mu \mathrm{M}(P=0.3)$ or $100 \mu \mathrm{M}(P=1.0)$.

The SVC score ranged from 1 to 5 (median: 4). A significant effect of SVC score on medium IL6 concentrations was demonstrated in the analysis of the effect of BCS and fat depot $(P=0.001)$, and in the analyses of the effect of FA treatment at $25 \mu \mathrm{M}(P=0.005), 50 \mu \mathrm{M}(P<$ $0.001)$, and $100 \mu \mathrm{M}(P<0.001)$. An increase of 1 unit in SVC score was associated with an increase of $3.2 \mathrm{ng} / \mathrm{mL}$ (1.3-5.1), $4.4 \mathrm{ng} / \mathrm{mL}$ (1.4-7.4), $5.2 \mathrm{ng} / \mathrm{mL}$ (2.3-8.2), and $4.7 \mathrm{ng} / \mathrm{mL}(2.2-7.1)$ in adjusted IL6 concentrations in the analysis of BCS and fat depot, and at $25 \mu \mathrm{M}, 50 \mu \mathrm{M}$, and $100 \mu \mathrm{M}$ FA treatment, respectively. No significant effects of SVC score on medium TNF $\alpha$ concentrations were demonstrated in the analysis of the effect of BCS and fat depot $(P=0.6)$ or the analyses of the effect of FA treatment at $25 \mu \mathrm{M} \quad(P=0.2), 50 \mu \mathrm{M} \quad(P=0.4)$ and $100 \mu \mathrm{M}(P=0.8)$.

\section{Effect of BCS and fat depot on adipokines}

BCS did not have significant effects on medium concentrations of adiponectin $(P=0.4)$, IL6 $(P=0.1)$, or TNF $\alpha$ $(P=0.8)$.

Fat depot had a significant effect on medium IL6 concentrations; adjusted mean medium IL6 concentration from visceral derived SVC was higher $(P=0.003)$ compared to subcutaneous derived SVC. No significant effect of fat depot was demonstrated on medium concentrations of TNF $\alpha(P=0.2)$ and adiponectin $(P=0.8$, Figs. 1 and 2).

\section{Effect of treatment on adipokines}

No significant effect on medium adiponectin concentration was observed following troglitazone treatment $(P=$ 0.4 , Fig. 2) or FA treatments at $25 \mu \mathrm{M}(P=0.2), 50 \mu \mathrm{M}$ $(P=0.8)$, or $100 \mu \mathrm{M}(P=0.7)$.

Interaction terms between fat depot and FA treatment were significant at 25,50 and $100 \mu \mathrm{M}$ in the analyses of IL6 and TNF $\alpha \quad(P<0.05$ for all), therefore results of separate analyses for each fat depot are reported.

FA treatment at $25 \mu \mathrm{M}, 50 \mu \mathrm{M}$, and $100 \mu \mathrm{M}$ had significant effects on medium IL6 concentration both in visceral $(P=0.029, P<0.001$, and $P<0.001$, respectively) and subcutaneous $(P=0.007, P<0.001$, and $P<0.001$, respectively) derived SVC. ARA treatment was associated with significantly higher medium IL6 concentration than the control at $25 \mu \mathrm{M}, 50 \mu \mathrm{M}$, and $100 \mu \mathrm{M}$ in subcutaneous $(P=0.045, P=0.002$, and $P<0.001$, respectively) and visceral $(P=0.034, P=0.001$, and $P<0.001$, respectively) derived SVC (Fig. 3a and b).

FA treatment at $25 \mu \mathrm{M}$ and $50 \mu \mathrm{M}$ had significant effects on medium TNF $\alpha$ concentrations in visceral $(P=$ 0.009 and $P<0.001$, respectively) and subcutaneous $(P<$ 0.001 and $P<0.001$, respectively) derived SVC. At 


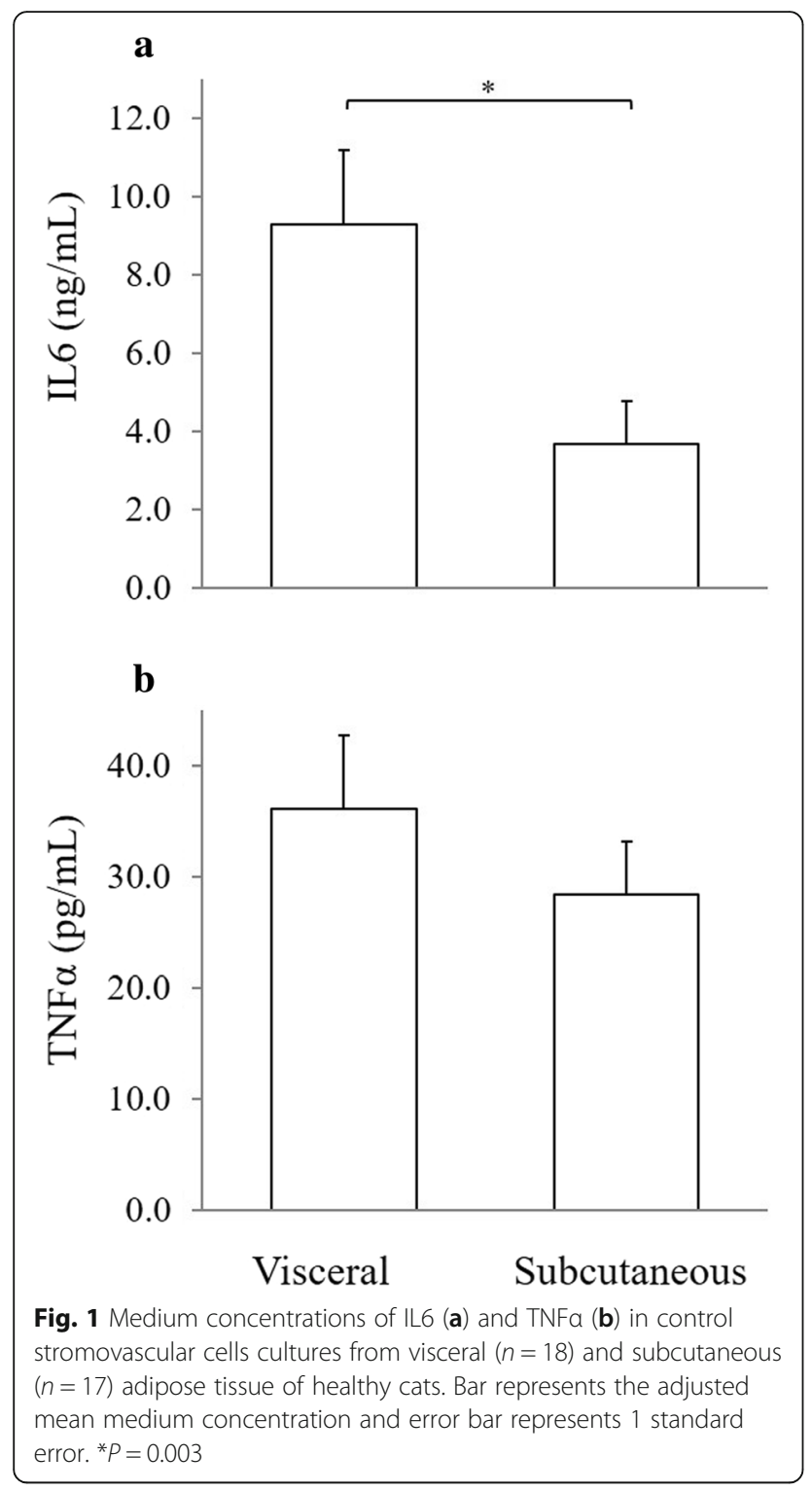

$100 \mu \mathrm{M}$, FA treatment had a significant effect on medium TNF $\alpha$ concentrations in subcutaneous $(P<0.001)$ but not in visceral $(P=0.1)$ derived SVC. ARA treatment at $25 \mu \mathrm{M}$ was associated with significantly lower medium TNF $\alpha$ concentrations than control in visceral $(P=0.032)$ derived SVC. EPA treatment was associates with significantly higher adjusted medium TNF $\alpha$ concentrations than control in subcutaneous derived SVC at $25 \mu \mathrm{M}, 50 \mu \mathrm{M}$, and $100 \mu \mathrm{M}(P=0.002, P=0.001$, and $P=0.015$, respectively $)$ and in visceral derived SVC at $50 \mu \mathrm{M}(P<0.001)$. PAM treatment was associated with significantly lower medium TNF $\alpha$ concentrations than control in subcutaneous derived SVC at $25 \mu \mathrm{M}$ and $50 \mu \mathrm{M}(P=0.001$ and $P=0.008$, respectively) (Fig. 3c and d).

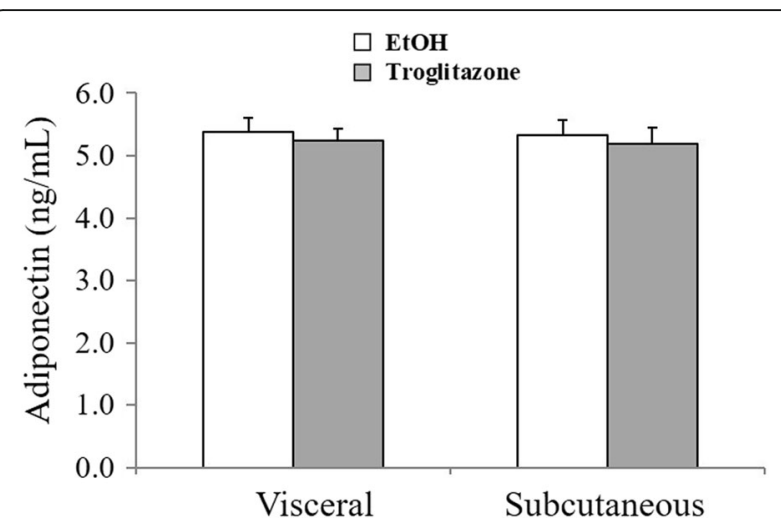

Fig. 2 Medium adiponectin concentrations in primary adipocytes control cultures and troglitazone-treated cultures from visceral and subcutaneous adipose tissue of healthy cats. Bar represents the adjusted mean medium concentration and error bar represents 1 standard error. In the visceral depot there were 18 control and 18 troglitazone-treated cultures. In the subcutaneous depot there were 17 control and 17 troglitazone-treated cultures

\section{Discussion}

Secretion of IL6 from feline adipose tissue SVC was higher in visceral compared to subcutaneous tissue. Although not statistically significant, a similar trend of difference was noted for TNFa. These findings are in agreement with previous reports of higher inflammatory cytokines secretion from visceral compared to subcutaneous tissue in humans and dogs $[6,30]$, but in contrast to findings of a study in cats that demonstrated higher IL6 expression in subcutaneous fat compared to visceral fat, while no difference in TNF $\alpha$ expression was found [31]. Since secretion of inflammatory cytokines increases with rising numbers of macrophages within the adipose tissue, and decreases with higher expression and activation of PPAR $\gamma$ in macrophages [32], the differences in secretion of inflammatory cytokines between the fat depots may result from higher numbers of SVC and lower expression of PPAR $\gamma$ in visceral than in subcutaneous adipose tissue, as was demonstrated in humans $[6,33]$. Studies in cats, on the other hand, showed higher expression of PPAR $\gamma 2$ in visceral compared to subcutaneous fat, as well as no difference in the number of macrophages and expression of PPAR $\gamma 1$ between the two fat depots $[12,31]$. The higher PPAR 2 expression is consistent with the lower IL6 expression in visceral fat found in that previous study [31], but in contrast to the finding of higher IL6 secretion in the present study. This disparity may result from the different culture and study design. In the previous study, IL6 expression was measured in whole adipose tissue that contains mostly mature adipocytes, whereas in the present study, IL6 expression was measured in the SVC fraction that contains 


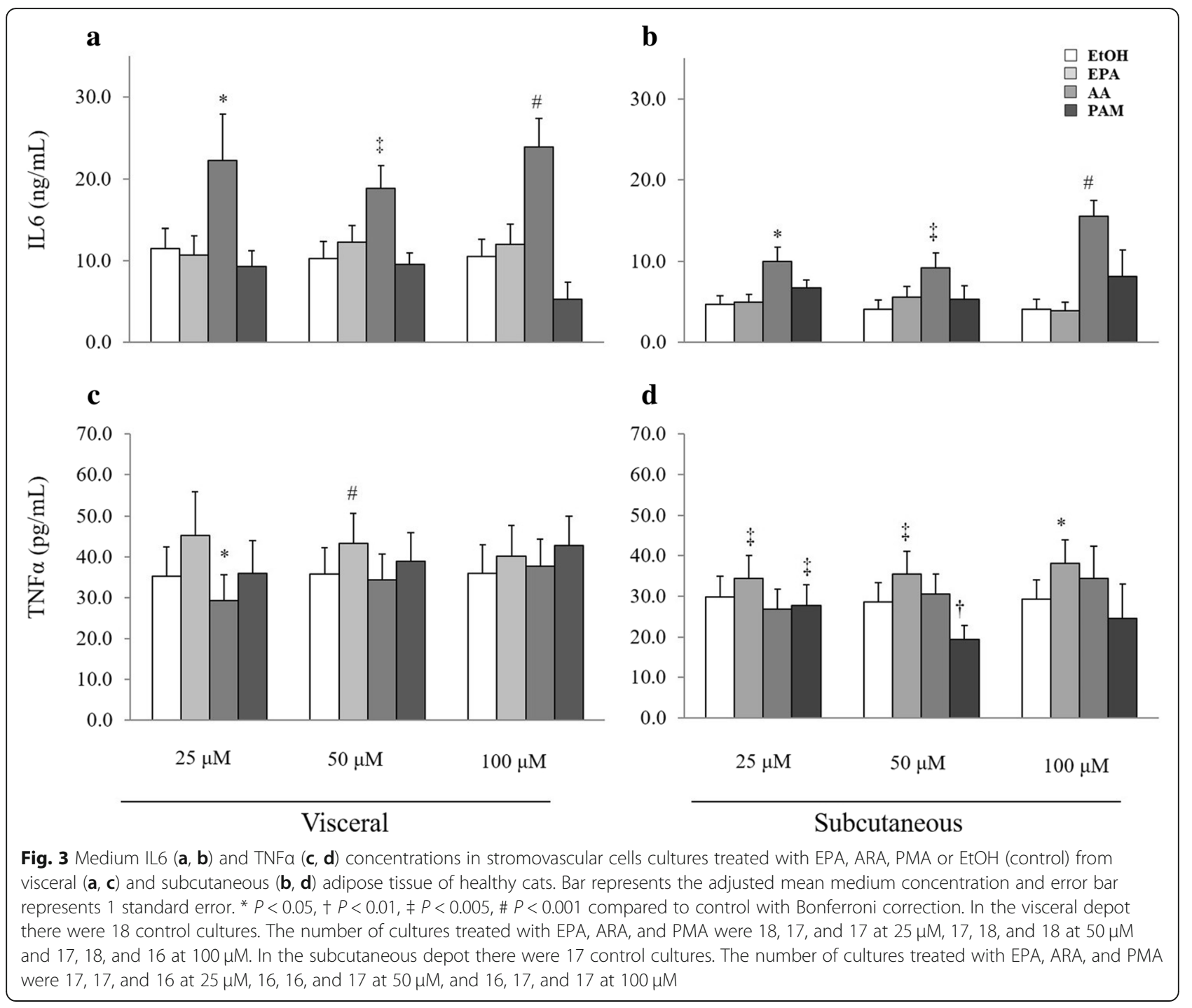

macrophages that are the main source of inflammatory cytokines secretion. Further studies are warranted to clarify the association between expression of inflammatory cytokines and expression of PPAR $\gamma$ and the number of macrophages in different fat depots and their specific fractions in cats.

Secretion of adiponectin from feline mature adipocytes was similar in visceral and subcutaneous adipose tissue depots. This finding is in agreement with a previous study in healthy cats [34], although other studies in cats reported higher adiponectin gene expression in visceral compared to subcutaneous fat [12, 31, 35]. These previous reports in cats are opposite to findings of most studies in humans and animals of lower adiponectin expression and secretion in visceral compared to subcutaneous fat $[30,36]$. Adiponectin production is higher in adipocytes of smaller size and with higher level of expression and activation of PPARy [37]. In cats, adipocytes derived from visceral fat were smaller compared to adipocytes derived from subcutaneous fat [31], and PPARy expression was found to be higher in visceral compared to subcutaneous fat [12, 35], providing support for the reported higher adiponectin expression in visceral fat in cats. The present study may have been limited to detect a potential difference in adiponectin secretion as no association between its concentration and PAV was found. Small sample size might have also been a limiting factor.

No association between BCS and concentrations of adipokines secreted into the culture medium was found in the present study. These results are in agreement with some previous studies in cats that did not reveal associations between body condition and expression or concentrations of adiponectin [35, 38-40], IL6 [31, 41], or TNF $\alpha$ [42]. In contrast, other studies in cats reported decreased circulating concentrations and adipose tissue mRNA expression of adiponectin [17-19, 31, 34, 41-46] 
and increased expression of TNF $\alpha[20,31]$ in obesity. Reduction in adipose tissue PPAR $\gamma$ expression has been demonstrated in obese cats [47], similar to findings in humans and rodent models [33]. In addition, adipocytes were larger in obese compared to lean cats [31]. The numbers of macrophages increase in adipose tissue in obesity in humans [7], while in cats, the number of Tlymphocytes was higher in obese compared to lean cats [31]. These changes are expected to result in decreased production of adiponectin by adipocytes and increased production of IL6 and TNF $\alpha$ by adipose tissue macrophages in obesity. The lack of the expected associations between BCS and medium adipokines concentrations in the present study may be due to the narrow range of body condition scores (5-6/9) among 16 of 18 of the cats, and as a result, the presence of only minimal obesity-related changes affecting adipokines secretion.

ARA had a stimulatory effect on IL6 secretion from adipose tissue SVC both in visceral and in subcutaneous depots, while EPA and PAM did not change IL6 secretion. In line with these findings in cats, ARA was demonstrated to increase secretion of IL6 as well as monocyte chemoattractant protein-1 in adipocytes cell line $[48,49]$. This increase was attenuated by EPA and was demonstrated to be mediated through activation of the nuclear transcription factor NF- $\mathrm{kB}$ [48]. This pattern of IL6 response to FA in feline adipose tissue may be viewed as consistent with the role of ARA in enhancing immune function [50]. These results in cats are different from our recent findings in canine adipose tissue SVC culture, where IL6 secretion was increased by PAM and decreased by EPA, while no effect of ARA was demonstrated [51], as well as results of studies in macrophages [52-54], adipocytes [55, 56], and endothelial cells [57].

The effect of FA on secretion of TNF $\alpha$ from feline SVC was less consistent among fat depots and FA concentrations, and included increased secretion in response to EPA treatment and decreased secretion in response to ARA and PAM treatments at some FA concentrations in subcutaneous or visceral SVC. These results are in contrast to previous reports that implicated SFA in induction of TNF $\alpha$ in murine and human macrophage cell lines [58] as well as in murine adipocytes cell line [59], while variable PUFA were shown to suppress its induction $[52,53,60]$. The stimulatory effect of EPA on TNF $\alpha$ secretion from feline SVC is surprising in view of the recognized anti-inflammatory effect of this FA. Interestingly, TNF $\alpha$ mRNA expression was increased by dexamethasone in differentiated canine adipocytes [61]. However, the explanation for this finding is unclear. An inhibitory effect of ARA on TNFa secretion was found only at a low FA concentration in visceral fat, and the explanation to this opposite effect of ARA on TNF $\alpha$ compared to IL6 is not clearly apparent. IL6 was previously shown to suppress TNF $\alpha$ production in skeletal muscle [62]. Although the presence of a similar interaction between these cytokines has not been shown in adipose tissue or macrophages, it may provide an explanation for the seemingly opposite effect of ARA on IL6 and TNF $\alpha$ in the present study. The inhibitory effect of PAM on TNF $\alpha$ secretion was present in subcutaneous fat only and was also unexpected. This finding is in contrast to findings in humans adipocytes, where an increase in mRNA expression of TNF $\alpha$ was found in response to PAM [63]. The inconsistent results of TNF $\alpha$ secretion, as well as the lack of association between SVC score and TNF $\alpha$ concentration may support the possibility of other unknown effects on its secretion and question the reliability of these results.

Secretion of adiponectin from mature feline adipocytes was not altered by troglitazone or any of the FA studied (EPA, ARA, or PAM). A potential effect of EPA to increase secretion of adiponectin is thought to be mediated through its interaction with PPAR [64]. Pharmacological agonists of PPAR $\gamma$ have been shown to increase circulating adiponectin concentrations in cats [14] similar to findings in humans and dogs $[15,16,65]$. The association between serum concentrations of adiponectin and EPA was positive in non-obese cats, but negative in obese cats [66]. Revealing a potential effect of troglitazone and FA on adiponectin secretion may have been hindered by the design of the present study. Secretion of adiponectin was evaluated in the first 2 days of culture only; therefore potential effects of troglitazone or FA following a longer time period in culture may be possible, as demonstrated previously [67]. In addition, the lack of association between adiponectin secretion and the volume of cultured adipocytes (PAV) also suggests that a potential effect on adiponectin was not reflected by measuring its secretion and evaluation of adiponectin gene expression could have provided additional information.

This study has several additional limitations, including the lack of detailed metabolic evaluation of the cats including serum concentrations of glucose, lipids, and adipokines, and lack of direct determination of cell viability and adipocytes size. Nevertheless, the significant positive association between SVC score and IL6 concentrations provides indirect evidence for the reliability of the culture system for evaluation of IL6 secretion, while the lack of association between PAV and adiponectin concentrations or SVC score and TNFa concentrations suggests that this study might have been limited by its design to reveal potential and consistent effects on adiponectin and TNF $\alpha$ secretion and further study is warranted. In addition, since only intact female cats were included in the study, the effect of gender on adipokines secretion could not be evaluated. 


\section{Conclusions}

The differential secretion of IL6 by fat depots in cats, with increased secretion of IL6 from visceral compared to subcutaneous adipose tissue SVC, suggests that visceral fat may be the primary contributor of adipose tissue origin to systemic inflammation. Since IL6 secretion was not associated with body condition, further investigation is required to determine whether visceral obesity in cats poses increased risk for metabolic disorders, such as type- 2 diabetes and hepatic lipidosis, similar to findings in human subjects. ARA was demonstrated to have a stimulatory effect on secretion of IL6 from feline adipose tissue, while no effect of EPA was demonstrated. A potential anti-inflammatory effect of fish oil may be mediated by substitution of ARA by EPA and a consequent reduction in IL6 secretion. Further studies are warranted to elucidate potential mechanisms.

\section{Methods \\ Cats}

Eighteen client-owned healthy intact female cats admitted to the Veterinary Teaching Hospital at Michigan State University for routine ovariohysterectomy were included in the study. Cats were determined to be healthy based on physical examination, absence of clinical signs indicating disease, and no abnormalities on a presurgical minimal data base including a complete blood count, kidney function, and liver enzymes. Body condition was evaluated using a body condition scoring (BCS) system on a 1-9 scale [68].

\section{Adipose tissue preparation and digestion}

At the time of ovariohysterectomy procedure, omental visceral adipose tissue samples were obtained from all cats $(n=18)$ and subcutaneous adipose tissue samples were obtained from cats that had sufficient fat directly under the skin incision $(n=17)$. The samples $(0.5-2.0 \mathrm{~g})$ were obtained aseptically. Each sample was immediately placed in $15 \mathrm{~mL}$ of fresh cell Dulbecco's modified Eagle's medium/ Ham's F12 medium (1:1) supplemented with $10 \mathrm{mM}$ HEPES, $10 \mathrm{mg} / \mathrm{mL}$ fatty acid free bovine serum albumin, $5 \mu \mathrm{g} / \mathrm{mL}$ ethanolamine, $0.1 \mathrm{ng} / \mathrm{mL}$ sodium selenite, $55 \mu \mathrm{mol} /$ $\mathrm{L}$ ascorbic acid, $200 \mathrm{nmol} / \mathrm{L}$ adenosine, $100 \mathrm{U} / \mathrm{mL}$ penicillin, $0.1 \mathrm{mg} / \mathrm{mL}$ streptomycin, and adjusted to a $\mathrm{pH}$ of 7.4 with approximately $1.2 \mathrm{~g} / \mathrm{mL}$ sodium bicarbonate at $4{ }^{\circ} \mathrm{C}$. Samples were transferred to the laboratory for processing within $30 \mathrm{~min}$.

Each tissue sample was washed with Hanks' Balanced Salt Solution (HBSS, Sigma H8265) to remove large blood clots; blood vessels and connective tissue were excised, and the remaining tissue was minced into $1-5 \mathrm{mg}$ fragments. The minced tissue was incubated in medium at room temperature for 30-60 min to remove soluble factors and then washed with Hanks' Balanced Salt Solution.
To separate mature adipocytes from SVC, tissue fragments of each tissue sample were separately immersed in cell culture medium ( $2 \mathrm{~mL} / \mathrm{g}$ tissue) that had been supplemented with collagenase (C6885, Sigma-Aldrich; $1 \mathrm{mg}$ / $\mathrm{mL})$ and digested for $60 \mathrm{~min}$ on a rotating platform (100 rotations $/ \mathrm{min}$ ) at $38{ }^{\circ} \mathrm{C}$. After incubation, the digest was passed through a $100 \mu \mathrm{m}$ nylon mesh and centrifuged $\left(450 \mathrm{Xg}, 22^{\circ} \mathrm{C}\right.$ ) for $5 \mathrm{~min}$. The mature adipocytes in the supernatant were separated from the pelleted SVC by aspiration. The cell pellet was treated with red blood cell lysing buffer $(1 \mathrm{~mL} / \mathrm{g}$ digested tissue) for $3 \mathrm{~min}$. Then, the mature adipocytes and SVC were separately washed in cell culture medium and centrifuged (450Xg, $22^{\circ} \mathrm{C}$ for $5 \mathrm{~min}$ ) 3 times. For each tissue sample, aliquots of $100 \mu \mathrm{L}$ adipocytes were each suspended in $1 \mathrm{~mL}$ fresh medium in $5 \mathrm{~mL}$ polypropylene tubes. SVC from each tissue sample were suspended in fresh medium at a final concentration of approximately 100,000 cells $/ \mathrm{mL}$ and seeded into a 24-well plate at $1 \mathrm{~mL}$ per well. Adipocytes and SVC were incubated in a humidified incubator with $5 \% \mathrm{CO}_{2}$ at $38^{\circ} \mathrm{C}$.

\section{Incubation and treatment}

Fatty acids (EPA: U-99-A, ARA: U-71-A, PAM: N-16-A; $\mathrm{Nu}$-Chek Prep, Inc) stock solutions $(50 \mathrm{mM})$ were prepared in absolute ethanol and stored at -20C in glass tubes protected from light. FA treatment media were prepared by dilution of stock solutions of fatty acids in cell culture medium to a final concentration of $25 \mu \mathrm{M}, 50 \mu \mathrm{M}$, or $100 \mu$ M. Troglitazone (Sigma, T2573) treatment medium was prepared by dilution into a final concentration of $10 \mu \mathrm{M}$. Control medium was prepared by dilution of the same volume of ethanol in cell culture medium. The final concentration of ethanol was $<0.2 \%$. Treatment and control media were then incubated at $38^{\circ} \mathrm{C}$ for $2 \mathrm{~h}$ prior to being added to the cells.

After $24 \mathrm{~h}$ of initial incubation, medium from all tubes (cultured mature adipocytes) and wells (cultured SVC) was aspirated. Then, either fresh control medium or treatment medium (troglitazone at $10 \mu \mathrm{M}$, or EPA, ARA, or PAM, at $25 \mu \mathrm{M}, 50 \mu \mathrm{M}$, or $100 \mu \mathrm{M}$ ) was added to each tube or well. Following $48 \mathrm{~h}$ of incubation, medium from each tube and well was collected and centrifuged $\left(15,000 \mathrm{Xg}, 4{ }^{\circ} \mathrm{C}\right)$ for 10 min; the supernatant was stored at $-80^{\circ} \mathrm{C}$ until analysis. Prior to medium collection, small aliquots of medium containing adipocytes were aspirated from each tube into capillary hematocrit tubes and centrifuged $\left(15,000 \mathrm{Xg}, 24^{\circ} \mathrm{C}\right)$ for $1 \mathrm{~min}$ in a microhematocrit centrifuge to measure the fractional occupation of the suspension by the adipocytes (packed adipocytes volume -PAV) [69]. Tubes with oil drops, indicating cell death, or PAV of $1 \%$ or less were excluded from further analysis. Culture plates were examined microscopically and wells were scored according to the percentage of well area occupied by SVC (SVC score; $1=10-20 \%, 2=21-40 \%, 3=41-60 \%, 4=$ 
$61-80,5=81-100 \%)$. Wells with detached cells or less than $10 \%$ area of occupation were excluded from further analysis.

\section{Medium analysis}

Samples of medium from cultured mature adipocytes were analyzed to determine concentrations of adiponectin and samples of medium from cultured SVC were analyzed to determine concentrations of IL6 and TNF $\alpha$. Medium concentrations of adiponectin, IL6 and TNF $\alpha$ were measured using commercially available assays (Mouse/rat Adiponectin ELISA, B-Bridge; Feline IL6 ELISA, R\&D Systems; Feline TNFa ELISA, R\&D Systems). Medium samples were diluted 1:100 in fresh medium in preparation for the IL6 assay. The dynamic ranges of the assays were $0.016-8 \mathrm{ng} / \mathrm{mL}$ for adiponectin, $6.1-2000 \mathrm{pg} / \mathrm{mL}$ in diluted samples for IL6, and 2.4$1000 \mathrm{pg} / \mathrm{mL}$ for TNF $\alpha$. Maximal intra- and inter-assay coefficients of variation were 5 and $7 \%$ for adiponectin, 3 and $7 \%$ for IL6, and 8 and $10 \%$ for TNF .

\section{Data analysis}

Associations between fat depot (visceral or subcutaneous) or BCS (1 to 9) and each outcome variable (medium concentrations of adiponectin, IL6, or TNF $\alpha$ ) were evaluated using generalized estimating equations (GEE). Troglitazone treatment (control, troglitazone) was added as a factor in the analysis of adiponectin. At each FA concentration $(25 \mu \mathrm{M}, 50 \mu \mathrm{M}$, and $100 \mu \mathrm{M})$, associations between FA treatment (control, EPA, ARA, PAM) and the same outcome variables were evaluated using GEE with fat depot as an additional factor and BCS and as an additional covariate. In all GEE models, PAV was entered as an additional covariate in the analysis of adiponectin and SVC score was entered as an additional covariate for IL6 and TNF $\alpha$ in order to control for the potential differences in numbers of adipocytes or SVC among test tubes or wells, respectively. Fat depot and treatment were set as within-subject variables. Interaction effects between fat depot and treatment or BCS were assessed. Non-significant interaction terms were removed from the models. Separate GEE models were analyzed and results were reported separately for each fat depot in analyses in which a significant $(P<0.05)$ interaction was observed. The residuals were normally distributed in all models. Bonferroni correction was applied for multiple post-hoc comparisons between different treatments and the control. Data were analyzed using a commercially available statistic program (SPSS 22.0 for Windows). $P \leq 0.05$ was considered statistically significant. Results of the GEE analyses are presented as means (95\% confidence interval) adjusted for the additional factors and covariates included in each analysis.

\section{Abbreviations}

ARA: Arachidonic acid (20:4n-6); BCS: Body condition score;

DHA: Docosahexaenoic acid (22:6n-3); EPA: Eicosapentaenoic acid (20:5n-3); FA: Fatty acids; GEE: Generalized estimating eqs.; IL: Interleukin; n3PUFA: n3 polyunsaturated fatty acids; PAM: Palmitic acid (16:0); PPAR: Peroxisome proliferator-activated receptor; SVC: Stromovascular cells; TNF: Tumor necrosis factor

\section{Acknowledgments}

The authors thank all cat owners for their willingness to take part in this study.

\section{Authors' contributions}

MM performed the adipose tissue culture study and the ELISA assays and was a major contributor to the study design and writing the first draft of the manuscript. SRB provided the knowledge and support for the adipose tissue culture methods. PAS contributed to the study design and interpretation of the data. All authors reviewed, read and approved the final manuscript.

Funding

Not applicable.

\section{Availability of data and materials}

The datasets used and/or analysed during the current study are available from the corresponding author on reasonable request.

\section{Ethics approval and consent to participate}

The study procedure was reviewed and approved by the institutional animal care and use committee at Michigan State University (Approval \# 12/09-18900). Written informed consent was obtained from all cat owners.

\section{Consent for publication}

Not applicable.

\section{Competing interests}

The authors declare that they have no competing interests.

\section{Author details}

${ }^{1}$ Department of Pathobiology and Diagnostic Investigation, Diagnostic Center for Population and Animal Health College of Veterinary Medicine, Michigan State University, East Lansing, MI 48824, USA. ${ }^{2}$ Present address: Hebrew University Veterinary Teaching Hospital, Koret School of Veterinary Medicine, The Hebrew University of Jerusalem, P.O. Box 12, 76100 Rehovot, Israel. ${ }^{3}$ Present address: Veterinary Consulting, Dewitt, MI 48820, USA.

Received: 25 February 2019 Accepted: 26 August 2019

Published online: 06 September 2019

\section{References}

1. Eisele I, Wood IS, German AJ, Hunter L, Trayhurn P. Adipokine gene expression in dog adipose tissues and dog white adipocytes differentiated in primary culture. Horm Metab Res. 2005;37(8):474-81.

2. Karbowska J, Kochan Z. Role of adiponectin in the regulation of carbohydrate and lipid metabolism. J Physiol Pharmacol. 2006; 57(Suppl 6):103-13.

3. Ouchi N, Kihara S, Arita Y, Okamoto Y, Maeda K, Kuriyama H, et al. Adiponectin, an adipocyte-derived plasma protein, inhibits endothelial NF -kappaB signaling through a CAMP-dependent pathway. Circulation. 2000; 102(11):1296-301.

4. Kadowaki T, Yamauchi T. Adiponectin and adiponectin receptors. Endocr Rev. 2005;26(3):439-51.

5. Fain JN, Bahouth SW, Madan AK. TNFalpha release by the nonfat cells of human adipose tissue. Int J Obes Relat Metab Disord. 2004;28(4):616-22.

6. Fain JN, Madan AK, Hiler ML, Cheema P, Bahouth SW. Comparison of the release of adipokines by adipose tissue, adipose tissue matrix, and adipocytes from visceral and subcutaneous abdominal adipose tissues of obese humans. Endocrinology. 2004;145(5):2273-82.

7. Weisberg SP, McCann D, Desai M, Rosenbaum M, Leibel RL, Ferrante AW Jr. Obesity is associated with macrophage accumulation in adipose tissue. J Clin Invest. 2003;112(12):1796-808. 
8. Hotamisligil GS. Mechanisms of TNF-alpha-induced insulin resistance. Exp Clin Endocrinol Diabetes. 1999;107(2):119-25.

9. Feingold KR, Grunfeld C. Role of cytokines in inducing hyperlipidemia. Diabetes. 1992;41:97-101.

10. Spiegelman BM. PPAR-gamma: adipogenic regulator and thiazolidinedione receptor. Diabetes. 1998:47(4):507-14.

11. Lee C-H \& Evans RM. Peroxisome proliferator-activated receptor- $\gamma$ in macrophage lipid homeostasis. Trends in Endocrinology \& Metabolism. 2002;13(8):331-35.

12. Zini E, Linscheid P, Franchini M, Kaufmann K, Monnais E, Kutter AP, et al. Partial sequencing and expression of genes involved in glucose metabolism in adipose tissues and skeletal muscle of healthy cats. Vet J. 2009;180(1):66-70.

13. Hoenig M, Ferguson DC. Effect of darglitazone on glucose clearance and lipid metabolism in obese cats. Am J Vet Res. 2003;64(11):1409-13.

14. Clark M, Thomaseth K, Dirikolu L, Ferguson DC, Hoenig M. Effects of pioglitazone on insulin sensitivity and serum lipids in obese cats. J Vet Intern Med. 2014;28(1):166-74.

15. Miyazaki Y, Mahankali A, Wajcberg E, Bajaj M, Mandarino L, DeFronzo RA. Effect of Pioglitazone on Circulating Adipocytokine Levels and Insulin Sensitivity in Type 2 Diabetic Patients. J Clin Endocrinol Metab. 2004;89(9): 4312-19.

16. Riera-Guardia N, Rothenbacher D. The effect of thiazolidinediones on adiponectin serum level: a meta-analysis. Diabetes Obes Metab. 2008;10(5):367-75.

17. Hoenig $\mathrm{M}$, Thomaseth $\mathrm{K}$, Waldron $\mathrm{M}$, Ferguson DC. Insulin sensitivity, fat distribution, and adipocytokine response to different diets in lean and obese cats before and after weight loss. Am J Physiol Regul Integr Comp Physiol. 2007;292(1):R227-34.

18. Ishioka K, Omachi A, Sasaki N, Kimura K, Saito M. Feline adiponectin: molecular structures and plasma concentrations in obese cats. J Vet Med Sci. 2009; 71 (2):189-94.

19. Belsito KR, Vester BM, Keel T, Graves TK, Swanson KS. Impact of ovariohysterectomy and food intake on body composition, physical activity, and adipose gene expression in cats. J Anim Sci. 2009;87(2):594-602.

20. Hoenig M, McGoldrick JB, deBeer M, Demacker PN, Ferguson DC. Activity and tissue-specific expression of lipases and tumor-necrosis factor alpha in lean and obese cats. Domest Anim Endocrinol. 2006;30(4):333-44.

21. Hotamisligil GS. Inflammation and metabolic disorders. Nature. 2006 444(7121):860-7.

22. Schreuder TC, Verwer BJ, van Nieuwkerk CM, Mulder CJ. Nonalcoholic fatty liver disease: an overview of current insights in pathogenesis, diagnosis and treatment. World J Gastroenterol. 2008;14(16):2474-86.

23. Zapata RC, Meachem MD, Cardoso NC, Mehain SO, McMillan CJ, Snead ER, et al. Differential circulating concentrations of adipokines, glucagon and adropin in a clinical population of lean, overweight and diabetic cats. BMC Vet Res. 2017;13(1):85.

24. Mazaki-Tovi M, Abood SK, Segev G, Schenck PA. Alterations in adipokines in feline hepatic lipidosis. J Vet Intern Med. 2013;27(2):242-9.

25. Wilkins C, Long RC Jr, Waldron M, Ferguson DC, Hoenig M. Assessment of the influence of fatty acids on indices of insulin sensitivity and myocellular lipid content by use of magnetic resonance spectroscopy in cats. Am J Vet Res. 2004;65(8):1090-9.

26. Oskarsson HJ, Godwin J, Gunnar RM, Thomas JX Jr. Dietary fish oil supplementation reduces myocardial infarct size in a canine model of ischemia and reperfusion. J Am Coll Cardiol. 1993:21 (5):1280-5.

27. McKenney JM, Sica D. Role of prescription omega-3 fatty acids in the treatment of hypertriglyceridemia. Pharmacotherapy. 2007;27(5):715-28.

28. von Schacky C. N-3 fatty acids and the prevention of coronary atherosclerosis. Am J Clin Nutr. 2000;71(1 Suppl):224S-7S.

29. Feskens $\mathrm{EJ}$, Bowles $\mathrm{CH}$, Kromhout D. Inverse association between fish intake and risk of glucose intolerance in normoglycemic elderly men and women. Diabetes Care. 1991;14(11):935-41.

30. Mazaki-Tovi M, Bolin SR, Schenck PA. Differential secretion of adipokines from subcutaneous and visceral adipose tissue in healthy dogs: association with body condition and response to troglitazone. Vet J. 2016;216:136-41.

31. Van de Velde H, Janssens GP, de Rooster H, Polis I, Peters I, Ducatelle R, et al. The cat as a model for human obesity: insights into depot-specific inflammation associated with feline obesity. Br J Nutr. 2013;110(7):1326-35.

32. Jiang C, Ting AT, Seed B. PPAR-gamma agonists inhibit production of monocyte inflammatory cytokines. Nature. 1998;391(6662):82-6.

33. Lefebvre AM, Laville M, Vega N, Riou JP, van Gaal L, Auwerx J, et al. Depot -specific differences in adipose tissue gene expression in lean and obese subjects. Diabetes. 1998;47(1):98-103.
34. Takashima S, Nishii N, Kato A, Matsubara T, Shibata S, Kitagawa H. Molecular cloning of feline resistin and the expression of resistin, leptin and adiponectin in the adipose tissue of normal and obese cats. J Vet Med Sci. 2016;78(1):23-8.

35. Riedel J, Badewien-Rentzsch B, Kohn B, Hoeke L, Einspanier R. Characterization of key genes of the renin-angiotensin system in mature feline adipocytes and during in vitro adipogenesis. J Anim Physiol Anim Nutr (Berl). 2016;100(6):1139-48,

36. Lihn AS, Bruun JM, He G, Pedersen SB, Jensen PF, Richelsen B. Lower expression of adiponectin mRNA in visceral adipose tissue in lean and obese subjects. Mol Cell Endocrinol. 2004;219(1-2):9-15.

37. Maeda N, Takahashi M, Funahashi T, Kihara S, Nishizawa H, Kishida K, et al. PPARgamma ligands increase expression and plasma concentrations of adiponectin, an adipose-derived protein. Diabetes. 2001;50(9):2094-9.

38. Witzel AL, Kirk CA, Kania SA, Bartges JW, Boston RC, Moyers T, et al. Relationship of adiponectin and its multimers to metabolic indices in cats during weight change. Domest Anim Endocrinol. 2015;53:70-7.

39. Bjornvad CR, Rand JS, Tan HY, Jensen KS, Rose FJ, Armstrong PJ, et al. Obesity and sex influence insulin resistance and total and multimer adiponectin levels in adult neutered domestic shorthair client-owned cats. Domest Anim Endocrinol. 2014;47:55-64.

40. Coradini M, Rand JS, Morton JM, Arai T, Ishioka K, Rawlings JM. Fat mass, and not diet, has a large effect on postprandial leptin but not on adiponectin concentrations in cats. Domest Anim Endocrinol. 2013:45(2):79-88

41. Hoenig M, Pach N, Thomaseth K, Le A, Schaeffer D, Ferguson DC. Cats differ from other species in their cytokine and antioxidant enzyme response when developing obesity. Obesity. 2013;21(9):E407-14.

42. Okada Y, Kobayashi M, Sawamura M, Arai T. Comparison of visceral fat accumulation and metabolome markers among cats of varying BCS and novel classification of feline obesity and metabolic syndrome. Front Vet Sci. 2017:4:17

43. Hoenig M, Jordan ET, Glushka J, Kley S, Patil A, Waldron M, et al. Effect of macronutrients, age, and obesity on 6- and 24-h postprandial glucose metabolism in cats. Am J Physiol Regul Integr Comp Physiol. 2011;301(6):R1798-807.

44. Muranaka S, Mori N, Hatano Y, Saito TR, Lee P, Kojima M, et al. Obesity induced changes to plasma adiponectin concentration and cholesterol lipoprotein composition profile in cats. Res Vet Sci. 2011;91(3):358-61.

45. Tvarijonaviciute A, Ceron JJ, Holden SL, Morris PJ, Biourge V, German AJ. Effects of weight loss in obese cats on biochemical analytes related to inflammation and glucose homeostasis. Domest Anim Endocrinol. 2012;42(3):129-41.

46. Tvarijonaviciute A, German AJ, Martinez-Subiela S, Tecles F, Ceron JJ. Analytical performance of commercially-available assays for feline insulin-like growth factor 1 (IGF-1), adiponectin and ghrelin measurements. J Feline Med Surg. 2012;14(2):138-46.

47. Hoenig M, Caffall Z, Ferguson DC. Triiodothyronine differentially regulates key metabolic factors in lean and obese cats. Domest Anim Endocrinol. 2008;34(3):229-37

48. Siriwardhana N, Kalupahana NS, Fletcher S, Xin W, Claycombe KJ, Quignard-Boulange A, et al. N-3 and n-6 polyunsaturated fatty acids differentially regulate adipose angiotensinogen and other inflammatory adipokines in part via NF-kappaB-dependent mechanisms. J Nutr Biochem. 2012;23(12):1661-7.

49. Cranmer-Byng MM, Liddle DM, De Boer AA, Monk JM, Robinson LE. Proinflammatory effects of arachidonic acid in a lipopolysaccharide-induced inflammatory microenvironment in 3T3-L1 adipocytes in vitro. Appl Physiol Nutr Metab. 2015;40(2):142-54

50. Zheng L, Zomerdijk TP, Van Den Barselaar MT, Geertsma MF, Van Furth R, Nibbering PH. Arachidonic acid, but not its metabolites, is essential for FcgammaR-stimulated intracellular killing of Staphylococcus aureus by human monocytes. Immunology. 1999;96(1):90-7.

51. Mazaki-Tovi M, Bolin SR, Schenck PA. Dietary fatty acids differentially regulate secretion of adiponectin and Interleukin-6 in primary canine adipose tissue culture. Lipids. 2018;53(2):205-16.

52. Martins de Lima-Salgado T, Coccuzzo Sampaio S, Fernanda Cury-Boaventura $M$, Curi R. Modulatory effect of fatty acids on fungicidal activity, respiratory burst and TNF-alpha and IL-6 production in $\mathrm{J774}$ murine macrophages. Br J Nutr. 2011:105(8):1173-9.

53. Wang S, Wu D, Lamon-Fava S, Matthan NR, Honda KL, Lichtenstein AH. In vitro fatty acid enrichment of macrophages alters inflammatory response and net cholesterol accumulation. Br J Nutr. 2009;102(4):497-501. 
54. Zhao G, Etherton TD, Martin KR, Vanden Heuvel JP, Gillies PJ, West SG, et al. Anti-inflammatory effects of polyunsaturated fatty acids in THP-1 cells. Biochem Biophys Res Commun. 2005;336(3):909-17.

55. Chakrabarti SK, Cole BK, Wen Y, Keller SR, Nadler JL. 12/15-lipoxygenase products induce inflammation and impair insulin signaling in 3T3-L1 adipocytes. Obesity (Silver Spring). 2009;17(9):1657-63.

56. Ajuwon KM, Spurlock ME. Palmitate activates the NF-kappaB transcription factor and induces IL-6 and TNFalpha expression in 3T3-L1 adipocytes. J Nutr. 2005;135(8):1841-6.

57. Staiger $\mathrm{H}$, Staiger K, Stefan N, Wahl HG, Machicao F, Kellerer M, et al. Palmitate-induced interleukin-6 expression in human coronary artery endothelial cells. Diabetes. 2004;53(12):3209-16.

58. Suganami T, Nishida J, Ogawa Y. A paracrine loop between adipocytes and macrophages aggravates inflammatory changes: role of free fatty acids and tumor necrosis factor alpha. Arterioscler Thromb Vasc Biol. 2005;25(10):2062-8.

59. Bradley RL, Fisher FF, Maratos-Flier E. Dietary fatty acids differentially regulate production of TNF-alpha and IL-10 by murine 3T3-L1 adipocytes. Obesity (Silver Spring). 2008;16(5):938-44.

60. Itoh M, Suganami T, Satoh N, Tanimoto-Koyama K, Yuan X, Tanaka M, et al. Increased adiponectin secretion by highly purified eicosapentaenoic acid in rodent models of obesity and human obese subjects. Arterioscler Thromb Vasc Biol. 2007:27(9):1918-25.

61. Ryan VH, German AJ, Wood IS, Hunter L, Morris P, Trayhurn P. Adipokine expression and secretion by canine adipocytes: stimulation of inflammatory adipokine production by LPS and TNFalpha. Pflugers Arch. 2010;460(3):603-16.

62. Pedersen BK, Steensberg A, Keller P, Keller C, Fischer C, Hiscock N, et al. Muscle-derived interleukin-6: lipolytic, anti-inflammatory and immune regulatory effects. Pflugers Arch. 2003;446(1):9-16.

63. Rodriguez-Pacheco F, Gutierrez-Repiso C, Garcia-Serrano S, Alaminos-Castillo MA, Ho-Plagaro A, Valdes $S$, et al. The pro-/anti-inflammatory effects of different fatty acids on visceral adipocytes are partially mediated by GPR120. Eur J Nutr. 2017;56(4):1743-52.

64. Kliewer SA, Sundseth SS, Jones SA, Brown PJ, Wisely GB, Koble CS, et al. Fatty acids and eicosanoids regulate gene expression through direct interactions with peroxisome proliferator-activated receptors alpha and gamma. Proc Natl Acad Sci U S A. 1997;94(9):4318-23.

65. Kasai S, Inoue T, Yoshitomi H, Hihara T, Matsuura F, Harada H, et al. Antidiabetic and hypolipidemic effects of a novel dual peroxisome proliferator-activated receptor (PPAR) alpha/gamma agonist, E3030, in db/ $\mathrm{db}$ mice and beagle dogs. J Pharmacol Sci. 2008;108(1):40-8.

66. Mazaki-Tovi M, Abood SK, Schenck PA. Effect of omega-3 fatty acids on serum concentrations of adipokines in healthy cats. Am J Vet Res. 2011; 72(9):1259-65.

67. Phillips SA, Ciaraldi TP, Oh DK, Savu MK, Henry RR. Adiponectin secretion and response to pioglitazone is depot dependent in cultured human adipose tissue. Am J Physiol Endocrinol Metab. 2008;295(4):E842-50.

68. Laflamme DP. Development and validation of a body condition score system for cats: a clinical tool. Feline Pract. 1997:25(5-6):13-8

69. Honnor RC, Dhillon GS, Londos C. CAMP-dependent protein kinase and lipolysis in rat adipocytes. I. Cell preparation, manipulation, and predictability in behavior. J Biol Chem. 1985;260(28):15122-9.

\section{Publisher's Note}

Springer Nature remains neutral with regard to jurisdictional claims in published maps and institutional affiliations.

Ready to submit your research? Choose BMC and benefit from:

- fast, convenient online submission

- thorough peer review by experienced researchers in your field

- rapid publication on acceptance

- support for research data, including large and complex data types

- gold Open Access which fosters wider collaboration and increased citations

- maximum visibility for your research: over $100 \mathrm{M}$ website views per year

At $\mathrm{BMC}$, research is always in progress.

Learn more biomedcentral.com/submissions 